\title{
CEM ANOS DE HISTÓRIA DO ENSINO DE FÍSICA NO BRASIL PELA ANÁLISE DE LIVROS DIDÁTICOS
}

\section{A HUNDRED YEARS OF THE HISTORY OF PHYSICS TEACHING IN BRAZIL BY TEXTBOOK ANALYSIS}

\author{
Daniel Perdigão ${ }^{1}$ \\ Michelle Zampieri Ipolito ${ }^{2}$
}

Resumo: A análise de livros didáticos é representativa do sistema educacional, pois os livros são a base do conteúdo escolar efetivo. Este estudo analisou qualitativamente 44 coleções de livros didáticos de Física, utilizados na escola secundária brasileira nos últimos cem anos. Foram observados os aspectos característicos das coleções e suas ênfases curriculares, referentes à forma de abordar os temas. Os objetivos foram identificar eventos históricos como causadores de mudanças no ensino de Física e estudar a transposição didática presente nesses livros ao longo do tempo. Foi possível estabelecer sete eras paradigmáticas para os livros, bem como os eventos de ruptura. As rupturas resultaram mais de ações do Poder Executivo do que de decisões do Legislativo. A transposição didática variou em cada período. Na década de 1920, valorizavam-se práticas técnicas e experimentais contemporâneas. Entre as décadas de 1930 e 1950, observou-se recuo a um cientificismo descolado da prática científica. Nos anos 1960, o conteúdo diminuiu e a variedade de ênfases aumentou. Nas décadas de 1970 e 1980, nova redução de conteúdo, visando preparar para os vestibulares. Em fins da década de 1980, iniciase uma transição, com adaptação dos livros existentes. Em fins dos anos 1990, novidades, como LDB, parâmetros curriculares e Enem, dirigiram o ensino de Física à formação de competências. Alterações do Enem em 2009 levaram à apresentação de ciência útil e contextualizada, com reforço conteudista. Novas ênfases curriculares no ensino de Física brasileiro poderão ser resultado da adoção da Base Nacional Comum Curricular.

Palavras-chave: Ensino médio. História do ensino de Física. Livros didáticos.

Abstract: The analysis of textbooks is representative of the educational system, since books are the basis of an effective school content. This study analyzed qualitatively 44 collections of Physics textbooks used in the Brazilian secondary school in the last hundred years. The characteristic features of the collections were observed, together with their curricular emphases, regarding the way to approach the themes. The goals were to identify historical events that have caused changes in Physics education and to study the didactic transposition present in these books over time. It was possible to establish seven paradigmatic eras for the books, as well as the rupture events. The disruptions resulted more from actions of the Executive branch than from Legislative decisions. The didactic transposition varied in each period. In the 1920 s, contemporary technical and experimental practices were valued. Between the 1930s and 1950s, there was a retreat to a scientism detached from the scientific practice. In the 1960s, the contents decreased, and the variety of emphases increased. In the 1970s and 1980s, there was a new reduction in the contents, focusing on the preparation for the

\footnotetext{
1 Doutor em Ensino de Ciências. Professor da Universidade de Brasília, E-mail: perdigao@unb.br.

${ }^{2}$ Doutora em Ciências. Professora da Universidade de Brasília, E-mail: ipolito@unb.br.
} 
college entrance exams. At the end of the 1980s, a transition began, with the adaptation of the existing books. In the late 1990s, novelties, such as LDB, curriculum parameters and the exam Enem, have directed the teaching of Physics to the formation of skills. Alterations in the exam Enem, in 2009, have led to the presentation of useful and contextualized science, with content reinforcement. New curricular emphases in the Brazilian Physics education may be the result of the adoption of the National Common Curricular Base..

Key words: High school. History of Physics education. Textbooks.

Data de submissão: 23.04 .2020

Data de aprovação: 17.05.2021

Identificação e disponibilidade:

(https://revista.univap.br/index.php/revistaunivap/article/view/2502, http://dx.doi.org/10.18066/revistaunivap.v27i56.2502).

\section{INTRODUÇÃO}

A história do livro didático começa no século $\mathrm{XV}$, com o surgimento da prensa móvel. A possibilidade de impressão em larga escala foi o que permitiu ao livro aumentar o seu alcance e passar a ter um propósito educacional. Embora o livro didático siga sendo, na maioria das vezes, um material impresso, seus objetivos mudaram muito ao longo dessa trajetória multissecular (JIMÉNEZ; PERALES, 2001).

Os livros didáticos se apresentam com três perfis históricos, não mutuamente excludentes. O primeiro perfil se assemelha, em método e estrutura, à literatura religiosa: perguntas e respostas de saberes seculares, mas remetendo à técnica de catequização. O segundo perfil é o de uma literatura técnica que vai sendo adaptada para se inserir no sistema escolar. O último é o de uma literatura descompromissada, de lazer. Por isso, inicialmente, não se via sua adesão ao ambiente escolar, mas, recentemente, teve alguns de seus aspectos adotados na Educação (CHOPPIN, 2004).

Porém, os livros didáticos não são objetivos ou factuais. São produtos culturais resultantes de complexas interações entre agentes econômicos e sociais. Ou seja, os livros didáticos são o resultado material de conflitos sociais, colaborando para converter as posições do grupo mais forte em hegemônicas ou permanentes (MACEDO, 2004). Portanto, o livro didático se associa às ambições dos poderes vigentes, sejam religiosos, políticos ou econômicos.

A aura de "verdade" que nossa sociedade atribui à palavra impressa desde os tempos de Lutero pode justificar esse interesse por dominar os manuais escolares. Em particular, o Estado tem o poder de estabelecer e regular o sistema educacional, permitindo sua interferência direta no conteúdo e na distribuição desse gênero de livros, algo que não costuma ser possível, no mesmo grau, para outros gêneros literários (BITTENCOURT, 1993).

Note-se que há um currículo acadêmico, escrito, e outro currículo prático. $\mathrm{O}$ discurso do currículo escrito sob as determinações do Estado mostra apenas a lógica projetada para legitimar a forma de escolaridade escolhida. Consequentemente, este currículo escrito não vai além de um testemunho público, cuja variação na prática seria não apenas possível, mas previsível (GOODSON, 2008). Essa variação é promovida por estudantes e professores, com base no livro didático. 
Mesmo que alguns professores não usem livros didáticos na sala de aula, eles os consultam para obter orientação sobre o que ensinar e como ensinar, estabelecendo-se o manual escolar como a referência mais consultada por discentes e docentes na prática (GATTI, 1997; MORTIMER, 1988). Nesse contexto, o livro didático seria um instrumento mais próximo do currículo prático do que do currículo teórico. Em outras palavras, o livro didático é a base do conteúdo escolar efetivo. Daí a necessidade de o Estado também precisar controlar o livro didático para poder controlar, de fato, o processo educacional.

Em alguns casos, há participação dos professores na escolha dos livros. Em uma análise superficial, isso significaria dizer que os docentes também exercem influência no seu conteúdo. Trata-se de uma conclusão precipitada: os professores não entram em contato direto com os aspectos mais profundos da relação entre a educação e seus efeitos, exceto em casos excepcionais (CHERVEL, 1990).

Por todas estas razões, a análise de livros didáticos é representativa do sistema educacional, podendo gerar grande quantidade de informações de valor para pesquisas acadêmicas (CORRÊA, 2000), não somente na área de Educação, mas também para Economia, Política, Sociologia, Antropologia, História, entre muitas outras.

É com esta visão transdisciplinar que propusemos o presente trabalho. Buscamos elementos nos livros didáticos utilizados no Brasil, ao longo dos últimos cem anos, que mostrassem as influências externas que sofreram, fazendo emergir os principais atores da trajetória da educação brasileira. Optamos pela análise de livros de Física, pois, em tese, estariam menos sujeitos às influências ideológicas de ocasião do que livros de disciplinas mais sensíveis, como História ou Geografia.

Embora trabalhos históricos sobre a educação brasileira do último século não sejam, de forma alguma, inéditos, buscamos inovar na forma de identificar os fatos relevantes, associando-os às mudanças que iam aparecendo, período a período, nos livros didáticos de Física secundária utilizados no Brasil nesse período. Um de nossos objetivos foi o de identificar eventos históricos como causadores de mudanças no ensino de Física no Brasil por meio da análise dos livros didáticos adotados no período. Com isso, poderemos avaliar, qualitativamente, o grau em que a Física escolar é influenciada pelas leis e pelas decisões de governo.

A emergência das Ciências foi fundamental para chegarmos ao atual estágio de nossa civilização, em evento tão notável que se convencionou chamá-lo de Revolução Científica (VELHO, 1999). O saber científico foi conquistando caráter de autoridade na sociedade, a ponto de criar a necessidade de uma formação científica na escola (WUO, 2000). Porém, apenas no início do século XX as Ciências conquistaram tal posição, passando a fazer parte do processo de admissão para as universidades (MATHIS, 1977) e, com isso, sendo inseridas como conteúdo curricular da educação básica.

Essa inserção é interpretada como a transposição didática do conhecimento científico da Física ao respectivo conhecimento escolar em livros (CHEVALLARD, 1991; ASTOLFI; DEVELAY, 1990), devendo se dar dentro de certos parâmetros. Essa conversão ou simplificação não pode ser tão intensa de modo a romper as conexões da Física escolar com os fenômenos físicos. Também não pode ser tão tênue e sutil a ponto de manter a Física abstrata e indecifrável para estudantes secundaristas, que, pela universalidade do nível médio, possuem os mais diversos interesses.

Dessa percepção, emerge outro objetivo para este trabalho: estudar a recontextualização ou transposição didática presente nesses livros. Afinal, as mudanças nos livros didáticos de Física ao longo do tempo refletem as mudanças nos 
objetivos da educação escolar e, em particular, do ensino de Física. Isto tem o potencial de contribuir para uma melhor seleção de livros didáticos pelo professor de Física e, também, chamá-lo à reflexão sobre a trajetória histórica do ensino de Física no Brasil.

\section{METODOLOGIA}

Neste estudo, foram qualitativamente analisadas 44 coleções de livros didáticos de Física utilizados no ensino Médio no Brasil nos últimos cem anos. O critério de seleção dos livros do século XX está a sua expressa menção em trabalho cujas autoras estudaram cerca de 250 obras brasileiras de Física secundária (MARTINS; HOSOUME, 2007). Em outras palavras, as autoras, ainda que tenham se baseado em tantas obras para sua pesquisa, selecionaram apenas três dezenas de obras para destacar na redação do seu trabalho, cujas bibliografias constam como notas de rodapé; elegemos nossas obras a partir dessa seleção.

O critério de seleção de obras do século XXI foi o da presença da obra entre os livros autorizados para compra, pelo governo brasileiro, por meio do Programa Nacional do Livro Didático do Ensino Médio (Pnlem), posteriormente unificado ao Programa Nacional do Livro Didático (PNLD). No Brasil, o ensino médio dura três anos. Os livros didáticos do ensino Médio, às vezes, são oferecidos em duas versões diferentes: volumes únicos, válidos para todos os três anos do ensino médio ou três volumes, um volume usado a cada ano. Os trabalhos em um único volume têm mais páginas, mas são resumidos em relação aos trabalhos originais em três volumes. Portanto, optamos por analisar os trabalhos em sua versão original, mesmo que a aprovada para compra governamental tenha sido a de volume único.

Essa eleição de obras, tanto do século XX quanto do século XXI, levou em conta outro critério: utilizamos apenas os trabalhos disponíveis em duas bibliotecas do Instituto de Física da Universidade de São Paulo, sendo uma delas especializada em livros didáticos. Isto ocorreu em função do amplo acervo disponibilizado para pesquisas na área e pela sua imediata disponibilidade para este estudo à época do levantamento.

Métodos de análise de livros didáticos já foram propostos e validados por muitos autores e grupos de pesquisa. Há quem sugira que os livros didáticos sejam classificados por suas ênfases curriculares (MOREIRA; AXT, 1986) ou por esquemas, nacionais e internacionais, a orientar o professor do nível secundário a analisar as obras e fazer a melhor escolha (ALVARENGA, 1991).

Neste trabalho, também temos a intenção de contribuir com elementos analíticos ao professor de Física. Por isso, selecionamos e adaptamos livremente algumas das categorias propostas nas bibliografias mencionadas, visando atingir os objetivos estabelecidos. Buscamos abordar os aspectos considerados na bibliografia como sendo mais importantes na avaliação e seleção de livros didáticos: objetivos materiais, tópicos focados, organização de conteúdo, nível de abstração etc., em tratamento de dados adequado para cada aspecto, obra e período.

Foram observadas as seguintes características, que consideramos estar entre as que revelam a transposição didática e a evolução histórica de forma mais sintética e direta, ou seja, que mais facilmente nos permitiriam atingir nossos objetivos: ênfases curriculares (MOREIRA; AXT, 1986) e aspectos característicos (ALVARENGA, 1991). Estas duas referências, por serem originais, detalham com maior precisão a metodologia de classificação e merecem ser consultadas na busca por aprofundamento dos detalhes metodológicos aplicados no presente estudo. 
Nossa intenção foi a de avaliar, comparativamente, a maneira de abordar os diferentes temas e, em seguida, fazer uma análise descritiva de cada período, em relação aos vários aspectos que os caracterizam. Ou seja, buscamos entender melhor a evolução do conteúdo dos livros de Física utilizados no Brasil nos últimos cem anos. Com isso, pudemos estudar a forma como se fez a transposição didática da Física ao longo dos tempos e identificar eventos históricos como causadores de mudanças no ensino de Física no Brasil.

Na literatura, é possível encontrar a sugestão de períodos na história das ideias pedagógicas no Brasil (SAVIANI, 2008) e de eras de desenvolvimento da educação científica no país (KRASILCHIK, 1987). Os lapsos temporais ali sugeridos são semelhantes e consistentes com os sete períodos de desenvolvimento do livro didático de Física do Brasil determinados a partir da análise das obras feita no presente trabalho. Usamos os marcos históricos citados pelos autores mencionados como orientação para garantir que tomaríamos pelo menos quatro livros diferentes para cada período. A análise mínima de quatro obras foi o que possibilitou o ajuste na determinação dos marcos históricos relevantes para o livro didático de Física, especificamente.

\section{RESULTADOS E DISCUSSÃO}

A análise dos livros nos levou a identificar sete períodos históricos de paradigmas de desenvolvimento do livro didático de Física secundária usado no Brasil. Trata-se de um ajuste e de uma expansão de classificação já realizada anteriormente, mas para livros de Química (MORTIMER, 1988), em função de observações originais do presente trabalho. Os sete períodos propostos são:

1) Período pré-reformas Francisco Campos e Capanema (1920-1932);

2) Período de vigência das reformas getulistas (1933-1961);

3) Período de vigência da primeira LDB (1962-1971);

4) Período de influência da lei 5692/1971 (1972-1985);

5) Período de redemocratização na educação (1986-1996);

6) Período de vigência da atual LDB, pré-Pnlem de Física (1997-2008);

7) Período do Pnlem/PNLD de Física e novo Enem (2009-2020).

A partir deste ponto, apresentaremos o resultado do trabalho descritivo dos livros de cada período, bem como a respectiva análise.

\subsection{PERÍODO PRÉ-REFORMAS FRANCISCO CAMPOS E CAPANEMA (1920-1931)}

No Brasil, os primeiros livros didáticos foram impressos no século XIX, com a instalação da Impressão Régia (BITTENCOURT, 1996). Um dos primeiros livros brasileiros de Física foi o "Lições Elementares de Physica segundo o programa de estudos do Collegio de Pedro II”, de Saturnino Soares de Meirelles, publicado em 1856 (SAMPAIO, 2007).

Ao longo daquele século, o objetivo principal dos autores foi deixando de ser a organização de cursos secundários e superiores. Na década de 1880, uma nova geração de autores, comprometida com as transformações sociais e políticas da época, como a abolição da escravidão e a queda da monarquia, juntou-se à causa da escolarização universal, criando livros que, sem abrir mão dos níveis mais altos de educação, também incluíam a escola primária (BITTENCOURT, 2004).

Até 1931, o Brasil não tinha um sistema educacional com uma estrutura oficial, 
de regras de abrangência nacional. Ao longo dos anos 1920, diversos governos empreenderam reformas educacionais locais, como o Ceará, sob Lourenço Filho; o Distrito Federal, sob Fernando de Azevedo; e Minas Gerais, sob Francisco Campos. Este último fora alçado a Ministro da Educação e Saúde por Getúlio Vargas em 1930. No cargo, implantou normas educacionais nacionais conhecidas como Reforma Francisco Campos. Com isso, pela primeira vez, a educação passou a ser padronizada em todo o território nacional (FGV, 2020).

Os livros didáticos utilizados no ensino médio no Brasil até a década de 1930 eram meros resumos gerais de cada disciplina. Os livros não apresentavam divisão entre séries ou anos escolares, já que essa segmentação também inexistia na prática. As obras que analisamos apresentam um arranjo de conteúdos singular, diferente do que é mais comum hoje, principiando com Mecânica, passando por Termodinâmica, Ondas, Óptica e Eletromagnetismo, podendo ir a elementos de Física Moderna. Havia, entre as obras da época, uma certa diversidade na sequência de conteúdos apresentada, com uma escolha mais livre por parte dos autores.

No período, os autores mostraram preocupação com as aplicações práticas do conhecimento, ilustrando as diferentes máquinas e situações físicas experimentais e lidando com seus diversos usos práticos. Os fenômenos são apresentados, inicialmente, sob uma abordagem qualitativa, e somente depois recebem enfoque quantitativo. Descrições de fatos e fenômenos da vida cotidiana são frequentes, e isso é uma característica distintiva das obras da década de 1920. Outra característica notável é a interdisciplinaridade expressiva entre a Física e outras ciências, como a Química, por exemplo. Inúmeras explicações se referem ao conhecimento de outras ciências.

Os trabalhos exibem grande número de ilustrações e diagramas, além de exercícios e problemas qualitativos incorporados ao final do trabalho ou, raramente, em cada capítulo. Na literatura, registra-se que isso também ocorreu com livros de Química, representando uma melhoria em relação aos livros do século XIX (MORTIMER, 1988).

Além disso, os trabalhos desse período foram atualizados continuamente em relação à ciência produzida na época. $O$ rápido crescimento da produção de saber científico no século $X X$, bem como a crescente diferenciação entre conhecimento científico e conhecimento escolar, ou seja, para o crescente hiato representado pela transposição didática, são possíveis explicações para o porquê de a atualização científica não ter sido tão perseguida pelos autores dos livros desde então.

\subsection{PERÍODO DE VIGÊNCIA DAS REFORMAS GETULISTAS (1932-1961)}

A Reforma Francisco Campos definiu a duração do Secundário em cinco anos, sendo que os últimos três anos previam a abordagem de conteúdos de Física. Os livros didáticos escritos para atender aos estudantes do curso colegial eram, pela primeira vez, obras seriais. Seu conteúdo deveria seguir o programa oficial de ensino estabelecido (GHIRALDELLI, 2006).

O Ministério da Educação e Saúde propôs nova reforma educativa em 1942. Consequentemente, foram estabelecidos novos parâmetros para os programas de livros didáticos. Esta reforma ganhou o nome do então ministro, Gustavo Capanema. A mais significativa alteração foi a de estender o Secundário para sete anos, sendo os últimos três anos chamados de Colégio, ou curso colegial. A Reforma Capanema abriu duas possibilidades de percursos formativos no curso colegial, o clássico e o científico, mas com uma desvalorização relativa deste último (DALLABRIDA, 2014). 
A atualização dos textos nos livros didáticos nesse período foi muito lenta, o que fica nítido quando observamos que esta foi a época de mais longa duração marcada para este trabalho. Poucas inovações foram vistas ao longo de três décadas. Mesmo a redemocratização do país, em meados da década de 1940, não foi capaz de alterar a dinâmica educacional, especialmente devido aos embates que atrasaram por quase quinze anos a promulgação de nossa primeira Lei de Diretrizes e Bases (LDB) (SANTOS; PRESTES; DO VALE, 2006).

Os livros didáticos de Física no período de influência getulista eram homogêneos em relação a como a maioria dos conceitos era tratada. Os livros deixaram de acompanhar o desenvolvimento científico e tecnológico contemporâneo, ficando estagnados. Esse descompasso começou a ser notado nas obras da década de 1930 ante as do período anterior. O atraso se aprofundou nas décadas de 1940 e 1950.

Uma das inovações da época foi a lista de exercícios incorporados no texto do capítulo, e não mais no final do volume. Praticamente todos esses exercícios são quantitativos, ao contrário do que aconteceu no período anterior. Portanto, foi nessa época que a matematização exagerada da Física do ensino Médio começou. Os trabalhos desse período são muito pouco ilustrados, muito menos do que no período anterior, mas, por outro lado, possuem extenso conteúdo teórico e tratamento matemático muito rigoroso, às vezes utilizando cálculo diferencial e integral.

Dentre os livros analisados, temos uma notável exceção: a obra de Aníbal Freitas, de 1949. Trata-se de uma obra singular, pois tem a organização do conteúdo muito diferente de qualquer outro trabalho da época. Por exemplo, o autor propõe o estudo do conceito de campo de forma integrada. Assim, o capítulo sobre campos elétricos é precedido pelo capítulo que trata de campos gravitacionais e sucedido pelo capítulo sobre campos magnéticos. O mesmo trabalho trata dos fenômenos de eletrização, em Eletrostática, de forma integrada ao tema da energia, algo que também é incomum.

Desta forma, no final da década de 1950, os livros didáticos de Física brasileiros estavam bastante obsoletos em relação à ciência produzida na época. Essa constatação é comum àquela encontrada em análise de livros brasileiros de Química desse mesmo período (MORTIMER, 1988). Observe-se, porém, que a situação não era diferente, por exemplo, nos Estados Unidos (SUMMERS, 1960).

\subsection{PERÍODO DE VIGÊNCIA DA PRIMEIRA LDB (1962-1971)}

A primeira LDB, de 1961, foi promulgada durante um período de democracia entre regimes ditatoriais. Isto significa que ela foi produto de um embate entre correntes distintas de pensamento. Para poder comportar visões distintas de educação, essa LDB permitia uma maior liberdade de ensino (MONTALVÃO, 2010). Uma análise da Lei Federal 4024/1961 é capaz de evidenciar grande flexibilidade de estrutura curricular ao curso colegial do Secundário, a partir da minimização dos dispositivos a regrar esse curso (MARCHELLI, 2014).

A consequência disso, para o presente trabalho, foi que a heterogeneidade dos livros de Física se tornou predominante. É difícil determinar uma tendência única dos livros dessa época. A maioria das obras tem abordagens entre as mais sucintas de todos os períodos analisados, com capítulos com letras e imagens grandes, muito poucas páginas dedicadas a cada assunto, objetividade excessiva e uso de meras enunciações e definições para substituir explicações elaboradas. Quanto à apresentação gráfica, os textos ainda protagonizavam os livros, enquanto ilustrações e títulos ocupavam pouco espaço. Em uns poucos livros do período, ainda há 
manutenção do padrão das décadas anteriores, a despeito de serem obras novas.

Note-se que a opção pela simplificação excessiva compromete o objetivo pedagógico do livro didático. Ainda que o conceito físico mencionado seja preciso, ele é novo para a maioria dos estudantes. Portanto, ele precisa ser acompanhado, ao menos, de explicação ou de exemplos, se a intenção é, de fato, garantir a aprendizagem da Física.

Os Estados Unidos começaram a reformar o seu ensino de Ciências um pouco antes, movidos pelo choque de estarem atrasados na corrida espacial após o lançamento bem-sucedido do primeiro satélite artificial da história pela União Soviética, o Sputnik-1, em 1957 (SANTOS, 2017). O marco temporal da mudança no Brasil, no entanto, é posterior, porque os projetos derivados do brutal financiamento do governo estadunidense chegaram aqui anos depois. Mas, sem dúvida, o evento também teve relação com a grande diversidade de obras na época: além das nacionais, passamos a ter as traduções nacionalizadas dos projetos estrangeiros.

Outro fator a justificar a variedade de abordagens e enfoques nas obras, algo que também ocorreu nos livros de Química da época (MORTIMER, 1988) foi o surgimento dos primeiros grupos de pesquisa brasileiros em Ensino de Ciências. Só que os pesquisadores da época, que chegaram à mesma conclusão, consideravam a diversidade de livros didáticos como negativa. As atas do I Simpósio Nacional de Ensino de Física, realizado em 1970, apontam a grande quantidade e diversidade de orientação dos livros didáticos como uma das justificativas para uma suposta baixa qualidade do ensino de Física na época (ALMEIDA, 1980). Não demorou muito para essa salutar diversidade acabar, pela intervenção de fatores negativos.

\subsection{PERÍODO DE INFLUÊNCIA DA LEI 5692/1971 (1972-1985)}

A alteração de dispositivos da LDB brasileira, por meio da Lei Federal 5692/1971, marca o início de um novo período paradigmático para os livros didáticos de Física no Brasil. Para a educação básica, esse foi o evento mais significativo de uma série de ocorrências do fim da década de 1960 e início da década de 1970, pois representou a consolidação legal do endurecimento do regime militar. A reforma universitária de 1968, determinada especialmente pela Lei Federal 5540/1968, também influenciou a dinâmica do ensino Secundário, ao exigir, no prazo de três anos, a unificação e a padronização dos exames de ingresso nas universidades, chamando-os de concurso vestibular.

Ainda que muitos dispositivos da Lei Federal 5692/1971 tenham sido revogados pela Lei Federal 7044/1982, especialmente no que se refere à profissionalização obrigatória, e que já observássemos movimentos rumo à redemocratização, como o sufrágio universal para a escolha de governadores em 1982, os livros somente começaram a mudar mais expressivamente na segunda metade da década de 1980, pois somente nessa época a mudança de ares começou a chegar na regulamentação e nas políticas educacionais, inclusive com o início das discussões em prol de uma nova LDB (BOLLMANN; AGUIAR, 2016).

$\mathrm{Na}$ década de 1970, os livros tiveram seu conteúdo ainda mais simplificado, como resultado da redução da carga horária das disciplinas científicas (ALMEIDA, 1980). Também foram criadas versões reduzidas dos livros para o segundo grau, os volumes únicos, com menos exemplos, explicações mais curtas, menos textos complementares, entre outros cortes. As obras da primeira metade da década de 1980 não são diferentes.

As obras didáticas do período são as primeiras em que há exercícios resolvidos, 
quase todos numéricos, além da proposição de perguntas reproduzidas dos exames vestibulares ao final de cada capítulo. Ou seja, a ênfase dos exercícios é guiada por fontes externas à própria obra e ao próprio autor. Isso reflete a crescente importância dos vestibulares ao longo do período. Ademais, com suas provas de questões quase exclusivamente quantitativas ou memorísticas, os autores das obras do período parecem ter sido induzidos a sacrificar tanto a exploração de conceitos quanto o número de exemplos práticos ou cotidianos da aplicação do conhecimento físico.

A educação da década de 1970 foi marcada por uma mentalidade tecnicista, segundo a qual se poderia educar por um método comportamentalista, do tipo estímulo-resposta (MORTIMER, 1988). Isso pode explicar o aumento significativo do número de exercícios nos livros, a ponto de haver obras que usam mais páginas para mostrar resoluções de questões de exames vestibulares do que para qualquer explicação teórica introdutória a cada tema. A profissionalização obrigatória no segundo grau pode, também, ter contribuído para essa situação, ao confundir educação com treinamento.

Durante o período, ganharam força induções gráficas, como grande destaque para títulos, conceitos e dicas considerados importantes pelos autores. Tais diagramações dirigem a leitura. O estudante não mais precisa se dar ao trabalho de escolher o que é importante: o autor já o fez, segundo seus critérios. Isso pode induzir a uma aprendizagem mecanizada. Além disso, passou a haver uma profusão de ilustrações, tabelas e outras formas de representação visual. Esse excesso de recursos visuais ilustrativos ou expositivos também tomaram espaço das explicações e de eventuais recursos visuais explicativos.

Em suma, foi neste período que se consolidou a transformação da Física do ensino Médio em um conhecimento propedêutico, introdutório para os estudos superiores, sem conexão com a experiência diária do aluno. Este caminho apenas serviu para diminuir o interesse dos alunos por esta ciência. Do mesmo modo, a opção de não mostrar o método científico que levou a um saber, uma lei ou uma teoria, pode ter incentivado os estudantes a entender a ciência como obra de gênios de lampejos de ideias brilhantes, e não, como na maioria dos casos, como resultado do trabalho árduo, longo e competente, levado a cabo por muitos cientistas, que trabalham juntos ou não, mas que discutem publicamente seus resultados no afã de consolidarem saberes.

\subsection{PERÍODO DE REDEMOCRATIZAÇÃO NA EDUCAÇÃO (1986-1996)}

Trata-se de um período de transição. A Constituição Federal de 1988, dos seus Art.205 ao Art.214, dita novas diretrizes gerais para a educação brasileira. Contudo, essas diretrizes demandam leis e decretos para sua normatização. Em outras palavras, a nova constituição induz à redação e à promulgação de uma nova LDB, mas isso só acontece em fins de 1996. Portanto, por mais de oito anos, a educação ainda foi regrada e sofreu as tendências autoritárias e já envelhecidas da Lei 5692/1971.

Porém, 1985 marca as primeiras ações institucionais rumo à redemocratização da educação, com o programa Educação para Todos (FREITAG; MOTTA; COSTA, 1987), mas, mais especialmente, com o Decreto Federal 91542/1985. Este dispositivo legal instituiu o Programa Nacional do Livro Didático (PNLD). Trata-se de um programa em que os professores das escolas públicas de primeiro grau poderiam eleger para a compra governamental o livro que desejassem, com alto grau de liberdade. 
Além do PNLD, iniciado em 1985, e da Constituição Federal de 1988, tivemos a edição do Plano Decenal de Educação para Todos em 1993 (BRASIL, 1993), antes da promulgação da LDB de 1996. Portanto, essa etapa de transição foi longa e lenta o suficiente para merecer a dedicação de um destaque a ela. Além disso, a mudança que ela representa não foi uniforme em todos os aspectos. Algumas alterações ocorreram de forma abrupta, outras lentamente; algumas foram mais rápidas no início do período, outras, mais ao fim.

Depois de sua pior fase, em termos da efetiva presença de uma busca por ensinar a Física como uma ciência da natureza, alguns dos livros começaram a mudar de perfil na segunda metade dos anos 1980, com uma intensificação desse movimento na década de 1990. A abertura política para discutir outros temas ligados à ciência física, dentro do contexto da disciplina e dos livros didáticos, estava dada. Certos autores aderiram à possibilidade, enriquecendo suas obras.

O período é caracterizado por uma diversidade de textos. Alguns permanecem vinculados ao paradigma anterior, sem alterações significativas: obras sintéticas, com poucas páginas dedicadas à teoria, poucas explicações e páginas cheias de questões numéricas de vestibulares resolvidas, frequentemente com mais da metade das páginas dedicadas a exercícios sugeridos ou resolvidos.

Algumas outras obras estão em plena transição: usam quadros complementares ou suplementares ao texto principal, que ilustram situações nas ciências ou na vida cotidiana, ou seja, situações de contextualização dos conceitos e teorias. Ainda que possamos imaginar que essa adição possa ter ocorrido pelo incentivo da abertura democrática, ela pode, também, ter se dado meramente como reflexo irrefletido a uma evolução homóloga nos livros estadunidenses de Física Geral para o ensino superior.

A introdução de perguntas abertas nos vestibulares, refletindo, também, a abertura política, começou a provocar alterações nos livros, ainda que tímidas e excessivamente lentas. O objetivo principal das obras seguiu sendo a preparação para os exames vestibulares. A alteração da distribuição do tipo de questão ou exercício presente das obras, reduzindo os itens quantitativos e aumentando os qualitativos, não parece ter sido ação espontânea de nenhum autor, mas mero reflexo da mudança nos exames vestibulares. Por isso, uma retomada da ideia de ciência para a formação do cidadão, uma opção de vanguarda de alguns livros da década de 1960, foi um processo muito mais tímido e vagaroso, tendo marcado intensamente apenas o período seguinte.

\subsection{PERÍODO DE VIGÊNCIA DA ATUAL LDB, PRÉ-PNLEM DE FÍSICA (1997-2008)}

A consolidação da transição observada nos doze anos de governos civis no Brasil só ocorreu em 1997, não somente pela Lei Federal 9394/1996, a nova LDB da Educação Nacional, promulgada no fim de dezembro de 1996, mas pela primeira publicação do Guia e Catálogo de Livros Didáticos como uma etapa do Programa Nacional do Livro Didático (PNLD). A publicação do guia representou uma etapa preliminar de seleção dos livros por técnicos e especialistas do governo; aos professores, restava a escolha dos livros dentre os aprovados nessa pré-seleção.

Os livros de ensino Médio só passaram a ser comprados pelo governo em 2005, vinte anos após a primeira versão do PNLD, com a chegada do Programa Nacional do Livro Didático do Ensino Médio (Pnlem). No caso específico dos livros de Física, o fornecimento gratuito de obras para escolas públicas só se deu em 2008. Este é um evento que marca o fim deste período, pois, até 2008, os livros não precisavam atender a requisitos de compra estatal, ainda que isso já fosse recomendado. 
Nessa perspectiva, além de a nova LDB determinar, com mais precisão, a direção a ser seguida pela educação brasileira, o pensamento na educação mudou. Desde o final dos anos 1990, observam-se mudanças nas propostas para a construção de projetos educacionais (BELMIRO, 2000). Essas propostas seriam mais amplas, inclusivas, interdisciplinares, holísticas, algo que mostra que o paradigma educacional mudou.

Os livros publicados no período se caracterizam pela preocupação com a inovação na metodologia e não apenas no conteúdo didático. Por exemplo, vários livros didáticos do período propõem e incentivam a realização de experimentos de maneira ricamente descrita e ilustrada, com materiais baratos ou cotidianos. Nas obras da década de 1920, os livros também mostravam grande número de experimentos e aparelhos científicos. Porém, há uma diferença significativa: há um século, o foco estava na formação técnica. Os experimentos voltavam-se a explicar o funcionamento de diversos aparelhos tecnológicos de uso profissional. Neste período mais recente, a intenção se volta para a formação científica para o cotidiano, com a exploração de objetos e fenômenos com os quais nos deparamos na vivência diária.

Outras características que remetem aos livros daquela época: a apresentação das explicações e teorias mais antigas para uma demonstração contraditória de teorias mais modernas; a adoção ampla de analogias inovadoras, sem limitá-las a exercícios resolvidos ou à intenção de fornecer ferramentas para a solução de problemas quantitativos reproduzidos de exames vestibulares.

No entanto, há um uso muito intensivo de quadros explicativos em parte dos trabalhos. Excluído esse conteúdo complementar ou suplementar, ou seja, considerado apenas o texto principal, o tratamento dos temas é tão conciso quanto nos livros da década de 1970. A descontinuidade parece deliberada, em que os autores acreditam que o conteúdo dos quadros pode ser ignorado por estudantes menos interessados. A consequência é a promoção de um estudo memorístico e superficial do conteúdo, pois a contextualização do saber físico está praticamente restrita ao conteúdo dos quadros.

Além disso, é comum que o leitor receba informações superficiais e seja incentivado a aprender mais sobre ela de fontes externas ao livro, em um processo de terceirização do processo de ensino e aprendizagem. Frequentemente, a fonte que o trabalho indica para consulta é a Internet, em páginas cujo controle e autoria não são do autor ou do editor do livro. Portanto, ainda que reconheçam a importância da incorporação de novas tecnologias no processo educacional, os livros tradicionais ainda não mediam esse processo de maneira satisfatória no período.

\subsection{PERÍODO DO PNLEM/PNLD DE FÍSICA E NOVO ENEM (2009-2020)}

A chegada do Programa Nacional de Livros Didáticos para o Ensino Médio (Pnlem) aos livros de Física, em 2008, introduziu novos paradigmas na composição dos livros didáticos, marcando o início de um novo período. Se, antes, os editores publicavam livros que atendiam às demandas de mercado, desde a chegada do Pnlem, precisam publicar livros que cumpram aos critérios do programa, porque somente os livros pré-selecionados podem ser adquiridos pelo governo. Como as compras estatais são muito superiores às vendas das editoras ao setor privado, o Pnlem, hoje incorporado ao PNLD, inevitavelmente induziu mudanças no formato das obras.

Porém, há de se observar a chegada de outra força muito poderosa a influenciar a redação dos livros didáticos brasileiros de Física: a alteração do Exame Nacional do 
Ensino Médio, em 2009. O Enem passou a ser, simultaneamente, um exame vestibular nacional unificado, um certificador de conclusão do ensino médio e uma prova classificatória para acesso a financiamentos e isenções na universidade privada e a programas universitários de mobilidade acadêmica (BARROS, 2014). Para isso, a prova aplicada aos estudantes passou a ter a nota determinada pela Teoria de Resposta ao Item, deixando de avaliar competências para voltar a ser conteudista (SILVA, 2016).

É possível que haja outros fatores a influenciar a consolidação deste período. São exemplos a valorização dos cursos de licenciatura por meio do Programa Institucional de Bolsa de Iniciação à Docência; a expansão desses cursos por meio da implantação do Sistema Universidade Aberta do Brasil e da Rede Federal de Educação Profissional, Científica e Tecnológica; o privilegiado campo de formação de professores nessa rede, por oferecer, no mesmo espaço, ensino médio e cursos de licenciatura. Porém, no atual estado da arte, não há indícios que nos permitam associar diretamente tais fatores às mudanças na redação de livros didáticos.

Ainda não podemos dizer se a reforma do Ensino Médio, determinada pela Lei Federal 13415/2017, e a implantação da Base Nacional Comum Curricular (BNCC) (BRASIL, 2018) marcarão um fim deste período paradigmático dos livros didáticos de Física usados no Brasil. O fato de não termos utilizado nenhuma obra tão recente neste estudo inviabiliza a consideração desse marco temporal. Ademais, é preciso ter em mente que o Enem praticamente não mudou desde 2009, o que indica a existência de uma barreira muito expressiva a uma mudança mais significativa nos livros.

A preocupação com uma ciência para o exercício da cidadania, que educa para o exercício do trabalho, da política e da vida social, é especialmente crescente e cada vez mais procurada pelos autores. Se, no período anterior, havia uma inclusão ainda tímida dessas temáticas, emendadas aos livros na forma de quadros complementares, a grande maioria dos livros mais recentes incorporaram essas referências à Física da vida cotidiana no texto principal. Há uma tendência de abandono de qualquer abordagem descontextualizada, embora ainda haja, em algumas obras, dificuldades em ir além de mostrar o contexto e efetivamente demonstrar a aplicação prática de uma teoria.

Em relação à opção por uma ênfase mais quantitativa ou mais qualitativa, as obras não têm uma tendência única. As obras mais voltadas à formação cidadã têm muitas equações aparecendo em destaque, porém, para conceitos específicos, e não para a maioria das explicações. Logo, há uma seleção mais criteriosa sobre o que mereceria abordagem quantitativa. Além disso, na maioria dos livros, a explicação de um fenômeno físico não se limita a uma prova matemática, como era comum nos anos 1970 e 1980.

Ainda há uma presença muito expressiva de abordagens quantitativas sem objetivo claro ou conexão direta com a compreensão do fenômeno. Em outras palavras, uma matematização que se sobrepõe à Física, e não uma que lhe presta serviço. Isso pode ser resultado de vários fatores: além da persistência de um Enem conteudista, pode haver uma tentativa de agradar parte dos professores de Física, que ainda se sentem mais confortáveis com a abordagem da Física eclipsada pela Matemática, paradigma sob o qual se formaram. Os autores dos livros acabam fazendo tais concessões para aumentar as chances de terem suas obras escolhidas pelos professores. Afinal, não basta aos autores e às editoras aprovar suas obras para constarem do Guia do Livro Didático do PNLD: é preciso, também, que os professores gostem da obra e a escolham para suas turmas.
A Tabela
1 busca
sintetizar
as características
predominantes dos livros 
estudados. Foram listadas duas ênfases curriculares mais intensas ou emergentes do período dentre as dez categorias propostas por Moreira e Axt (1986), e alguns aspectos característicos dentre os destacados por Alvarenga (1991).

Tabela 1 - Síntese das características predominantes dos livros por período (continuação)

\begin{tabular}{cc}
\hline Período & Énfases curriculares \\
\hline $1920-1931$ & $\begin{array}{c}\text { Fundamentação sólida } \\
\text { Ciência integrada }\end{array}$
\end{tabular}

$1932-1961$

$1962-1971$

1972-1985

$1986-1996$

$1997-2008$
Habilidades científicas

Estrutura da ciência

Explicações corretas Tecnologia educacional

Explicações corretas Fundamentação sólida

Indivíduo como explicador Estrutura da ciência

Ciência/tecnologia/sociedade Habilidades científicas
Aspectos característicos

Aspecto qualitativo cuidadoso

Aspecto quantitativo afrouxado

Experimentação técnica

Exercícios qualitativos

Tecnologia técnica contemporânea

Transposição de ênfase tecnológica

Aspecto qualitativo estagnado

Aspecto quantitativo rigoroso

Experimentação científica obsoleta

Exercícios quantitativos

Tecnologia abandonada

Transposição de ênfase científica

Aspecto qualitativo comprimido

Aspecto quantitativo preeminente

Experimentação descontextualizada

Exercícios em predomínio quantitativo

Tecnologia como justificativa da ciência

Transposição diversificada

Aspecto qualitativo negligenciado

Aspecto quantitativo eclipsante

Experimentação ignorada

Exercícios numéricos de vestibulares

Tecnologia ignorada

Transposição descolada do saber original

Aspecto qualitativo restituído

Aspecto quantitativo sustentado

Experimentação retomada

Exercícios com ênfase nos vestibulares

Tecnologia em recontextualização

Transposição em transição

Aspecto qualitativo renovado

Aspecto quantitativo recuado

Experimentação acessível

Exercícios qualitativos e quantitativos

Tecnologia como tema motivador

Transposição com novas analogias 
Tabela 1 - Síntese das características predominantes dos livros por período (conclusão)

\begin{tabular}{ccc}
\hline Período & Énfases curriculares & Aspectos característicos \\
\hline & & Aspecto qualitativo contextualizado \\
& Aspecto quantitativo epitomado \\
$2009-2020$ & Ciência do cotidiano & Experimentação de aplicação prática \\
& Autorrealização & Exercícios mais reflexivos \\
& Tecnologia do cotidiano \\
& Transposição guiada pela contextualização \\
\hline
\end{tabular}

Fonte: Os autores.

\section{CONCLUSÕES}

Esta análise dos livros didáticos utilizados no país durante os últimos cem anos nos permitiu identificar alguns eventos como causadores de mudanças no ensino de Física no Brasil. Isso nos levou a perceber que a Física, como disciplina do ensino Médio brasileiro, move-se muito mais pela influência do Estado, seja por meio do Executivo ou do Legislativo, do que pela intervenção de outros grupos, como professores ou empresários da educação, ou pela evolução do ensino de Física no exterior.

Ações do Poder Executivo marcaram mais mudanças de paradigma do que decisões do Legislativo. Mesmo a Lei Federal 5692/1971, ainda que seja obra do Legislativo, não foi discutida amplamente com a sociedade como foram as duas Leis de Diretrizes e Bases, cujos debates se prolongaram por mais de dez anos cada uma, sendo resultado da acomodação de várias correntes de pensamento da sociedade. Mais recentemente, a reforma do Ensino Médio de 2018, se marcar uma nova mudança de padrão nos livros de Física, também deverá ser contabilizada no grupo das leis pouco discutidas, por ser resultado da conversão de uma Medida Provisória, baseada em discussões que raramente foram além do Ministério da Educação, em Lei.

O outro objetivo para este trabalho foi o de evidenciar a transposição didática presente nos livros, o que foi feito a partir da análise da apresentação dos textos, da forma de abordagem do conteúdo e da definição das ênfases curriculares mais relevantes de cada período. A síntese analítica final reuniu as principais características de cada período, embora seja simplificação que oculta nuances, detalhes e exceções.

Até fins da década de 1920, os livros valorizavam práticas técnicas e experimentais, buscando acompanhar a ciência contemporânea. As fronteiras mais tênues entre as ciências também se reproduziam nas obras. Entre as décadas de 1930 e 1950, houve recuo a um cientificismo descolado da prática científica, com estagnação de conteúdos e abordagens. Nos anos 1960, assistimos a uma diversificação das diretrizes de ensino, culminando com uma variedade grande de enfoques, muitos como fruto de projetos educacionais, mas, na maioria dos casos, com redução de conteúdo.

Nos anos 1970 e metade dos 1980, o conteúdo das obras diminuiu ainda mais, devido à profissionalização obrigatória e à redução do tempo das aulas de Física. $A$ ênfase passou à preparação para exames vestibulares de questões quantitativas e memorísticas. Em fins da década de 1980 e início da década seguinte, inicia-se uma adaptação dos livros, com inclusão de quadros suplementares, com temas como história da ciência e fenômenos físicos curiosos relacionados à teoria apresentada.

Em fins dos anos 1990 e ao longo da década de 2000, a nova LDB, novos 
parâmetros curriculares e um Enem voltado à avaliação de competências dirigiram o ensino de Física a um uso social, cidadão, e ao desenvolvimento de habilidades. Alterações do Enem e a chegada do Pnlem à área de Física levaram os livros da década de 2010 à tentativa de apresentação de uma ciência útil ao estudante, cada vez mais contextualizada no cotidiano, com a incorporação desses conteúdos no corpo do texto.

Esta trajetória centenária sugere haver, ainda, muito a fazer para melhorar o ensino de Física. Um dos aspectos mais preocupantes é a persistência em pôr o aspecto quantitativo no centro das atenções, em lugar de priorizar a compreensão dos princípios físicos e de suas relações com os fenômenos naturais que envolvem o aluno em sua vida cotidiana. É importante termos um currículo prático que promova o questionamento e a problematização, que incentive o uso do raciocínio, que estimule à ação. A Base Nacional Comum Curricular fornece um currículo teórico nesse sentido. Enem e PNLD podem ajudar a fazer desse currículo teórico um currículo prático de qualidade, destinando o próximo paradigma dos nossos livros de Física a ser o melhor dos tempos.

\section{REFERÊNCIAS}

ALMEIDA Junior, João Baptista de. A evolução do ensino de Física no Brasil: $2^{a}$ parte. Revista de Ensino de Física, São Paulo, v.2, n.1, p.55-73, 1980. Disponível em: http://www.sbfisica.org.br/rbef/pdf/vol02a06.pdf. Acesso em: 4 abr. 2020.

ALVARENGA Alvares, Beatriz. Livro Didático: análise e seleção. In: MOREIRA, Marco Antonio; AXT, Rolando. (Orgs.) Tópicos em Ensino de Ciências. Porto Alegre: Sagra, 1991. Disponível em:

https://edisciplinas.usp.br/pluginfile.php/4368998/mod resource/content/2/texto\%203 .pdf. Acesso em: 3 abr. 2020.

ASTOLFI, Jean-Pierre; DEVELAY, Michel. A didática das ciências. Campinas: Papirus, 1990.

BARROS, Aparecida da Silva Xavier. Vestibular e Enem: um debate contemporâneo. Ensaio: avaliação e políticas públicas em educação, v. 22, n. 85, p. 1057-1090, out./dez.2014. Disponível em: https://doi.org/10.1590/S0104-40362014000400009. Acesso em: 7 abr. 2020.

BELMIRO, Celia Abicalil. A imagem e suas formas de visualidade nos livros didáticos de Português. Educação \& Sociedade, v. 21, n. 72, 2000. Disponível em: https://doi.org/10.1590/S0101-73302000000300002. Acesso em: 2 abr.2020.

BITTENCOURT, Circe Maria Fernandes. Livro didático e conhecimento histórico: uma história do saber escolar. 1993. 383 f. Tese (Doutorado em História). Faculdade de Filosofia, Letras e Ciências Humanas da Universidade de São Paulo, São Paulo, 1993.

BITTENCOURT, Circe Maria Fernandes. O que é o livro didático? In: SEMINÁRIO NACIONAL SOBRE LITERATURA INFANTO-JUVENIL, LIVRO DIDÁTICO E PARTICIPAÇÃO DA COMUNIDADE NA FORMAÇÃO DE LEITORES, 2., 1995, São Paulo. Anais...: leitura e literatura para a infância e a juventude. São Paulo, SP: 
Faculdades Teresa Martin, 1996.

BITTENCOURT, Circe Maria Fernandes. Autores e editores de compêndios e livros de leitura (1810-1910). Educação e Pesquisa, v. 30, n. 3, p. 475-491, 2004.

BOLLMANN, Maria da Graça Nóbrega; AGUIAR, Letícia Carneiro. LDB: projetos em disputa: da tramitação à aprovação em 1996. Retratos da Escola, Brasília, v.10, n.19, p.407-428, jul./dez.2016. Disponível em:

http://retratosdaescola.emnuvens.com.br/rde/article/download/703/705. Acesso em: 8 abr. 2020.

BRASIL. Ministério da Educação. Plano Decenal de Educação para Todos. Brasília, DF: MEC, 1993. Disponível em:

http://www.dominiopublico.gov.br/download/texto/me001523.pdf. Acesso em: 8 abr. 2020.

BRASIL. Ministério da Educação. Base Nacional Comum Curricular: educação é a base. Brasília, DF: Ministério da Educação, 2018. Disponível em:

http://basenacionalcomum.mec.gov.br/images/BNCC El EF 110518 versaofinal sit e.pdf. Acesso em: 6 abr. 2020.

BRASIL. Constituição Federal. Brasília, DF: Presidência da República, 1988. Disponível em: http://www.planalto.gov.br/ccivil 03/constituicao/constituicao.htm. Acesso em: 6 abr. 2020.

BRASIL. Lei 4024, de 20 de dezembro de 1961. Fixa as Diretrizes e Bases da Educação Nacional. Brasília, DF: Presidência da República, 1961. Disponível em: http://www.planalto.gov.br/ccivil 03/leis/L4024.htm. Acesso em: 31 mar. 2020.

BRASIL. Lei 5540, de 28 de novembro de 1968. Fixa normas de organização e funcionamento do ensino superior e sua articulação com a escola média, e dá outras providências. Brasília, DF: Presidência da República, 1968. Disponível em: http://www.planalto.gov.br/ccivil 03/leis/L5540.htm. Acesso em: 9 abr. 2020.

BRASIL. Lei 5692, de 11 de agosto de 1971. Fixa Diretrizes e Bases para o ensino de $1^{\circ}$ e $2^{\circ}$ graus, e dá outras providências. Brasília, DF: Presidência da República, 1971. Disponível em: http://www.planalto.gov.br/ccivil 03/leis/L5692.htm. Acesso em: 31 mar. 2020.

BRASIL. Lei 7044, de 18 de outubro de 1982. Altera dispositivos da Lei $n^{\circ} 5.692$, de 11 de agosto de 1971, referentes a profissionalização do ensino de $2^{\circ} \mathrm{grau}$. Brasília, DF: Presidência da República, 1982. Disponível em: http://www.planalto.gov.br/ccivil 03/leis/L7044.htm. Acesso em: 9 abr. 2020.

BRASIL. Lei 9394, de 20 de dezembro de 1996. Estabelece as diretrizes e bases da educação nacional. Brasília, DF: Presidência da República, 1996. Disponível em: http://www.planalto.gov.br/ccivil 03/leis/19394.htm. Acesso em: 31 mar. 2020.

BRASIL. Lei 13415, de 16 de fevereiro de 2017. Altera as Leis $n{ }^{\circ} 9.394$, de 20 de dezembro de 1996, que estabelece as diretrizes e bases da educação nacional, e 
11.494, de 20 de junho 2007, que regulamenta o Fundo de Manutenção e Desenvolvimento da Educação Básica e de Valorização dos Profissionais da Educação, a Consolidação das Leis do Trabalho - CLT, aprovada pelo Decreto-Lei $n^{\circ}$ 5.452, de $1^{\circ}$ de maio de 1943, e o Decreto-Lei $n^{\circ} 236$, de 28 de fevereiro de 1967; revoga a Lei $n^{\circ} 11.161$, de 5 de agosto de 2005; e institui a Política de Fomento à Implementação de Escolas de Ensino Médio em Tempo Integral. Brasília, DF: Presidência da República, 2017. Disponível em: http://www.planalto.gov.br/ccivil 03/ Ato2015-2018/2017/Lei/L13415.htm. Acesso em: 31 mar. 2020.

BRASIL. Decreto 91542, de 19 de agosto de 1985. Institui o Programa Nacional do Livro Didático, dispõe sobre sua execução e dá outras providências. Brasília, DF: Câmara dos Deputados, 1985. Disponível em: https://www2.camara.leg.br/legin/fed/decret/1980-1987/decreto-91542-19-agosto1985-441959-publicacaooriginal-1-pe.html. Acesso em: 31 mar. 2020.

CARNEIRO, Maria Helena da Silva. As imagens no livro didático. In: ENCONTRO NACIONAL DE PESQUISA EM EDUCAÇÃO EM CIÊNCIAS, 1., 1997, Águas de Lindoia. Atas[...]. Águas de Lindoia, SP: Associação Brasileira de Pesquisa em Educação em Ciências, 1997.

CHERVEL, André. História das disciplinas escolares: reflexões sobre um campo de pesquisa. Teoria \& Educação, Porto Alegre, n. 2, p. 177-229, 1990. Disponível em: https://moodle.fct.unl.pt/pluginfile.php/122510/mod resource/content/0/Leituras/Cher vel01.pdf. Acesso em: 9 abr. 2020.

CHEVALLARD, Yves. La transposición didáctica: del saber sabio al saber enseñado. Buenos Aires: Aique, 1991. Disponível em: https://www.academia.edu/35432408/La transposici\%C3\%B3n did\%C3\%A1ctica D el saber sabio al saber ense\%C3\%B1ado. Acesso em: 31 mar. 2020.

CHOPPIN, Alain. História dos livros e das edições didáticas: sobre o estado da arte. Educação e Pesquisa, São Paulo, v. 30, n. 3, p. 549-566, 2004. Disponível em: https://doi.org/10.1590/S1517-97022004000300012. Acesso em: 2 abr. 2020.

CORREAA, Rosa Lydia Teixeira. O livro escolar como fonte de pesquisa em História da Educação. Cadernos Sedes, Campinas, v. 20, n. 52, p. 11-24, 2000. Disponível em: http://www.scielo.br/pdf/ccedes/v20n52/a02v2052.pdf. Acesso em: 4 abr. 2020.

DALLABRIDA, Norberto. O MEC-Inep contra a Reforma Capanema: renovação do ensino secundário na década de 1950. Perspectiva, Florianópolis, v. 32, n. 2, p. 407-427, maio/ago. 2014. Disponível em: http://dx.doi.org/10.5007/2175795X.2014v32n2p407. Acesso em: 3 abr. 2020.

FGV. Fundação Getúlio Vargas. Centro de Pesquisa e Documentação de História Contemporânea do Brasil. A Era Vargas: dos anos 20 a 1945. Anos 20: Questão Social: Reformas Educacionais. Rio de Janeiro: CPDOC; FGV, 2020. Disponível em: https://cpdoc.fgv.br/producao/dossies/AEraVargas1/anos20/QuestaoSocial/Reformas Educacionais. Acesso em: 5 abr. 2020. 
FREITAG, Barbara; MOTTA, Valeria Rodrigues; COSTA, Wanderly Ferreira. 0 estado da arte do livro didático no Brasil. Brasília, DF: Instituto Nacional de Estudos e Pesquisas Educacionais, 1987. Disponível em:

http://www.dominiopublico.gov.br/download/texto/me001994.pdf. Acesso em: 6 abr. 2020.

GATTI JÚNIOR, Décio. Livros didáticos, saberes disciplinares e cultura escolar: primeiras aproximações. Revista História da Educação, Pelotas, v. 1, n. 2, p. 29 50, set.1997. Disponível em: https://seer.ufrgs.br/asphe/article/view/30663. Acesso em: 08 maio 2021.

GHIRALDELLI Júnior, Paulo. A organização do ensino legada pelo Estado Novo. In: GHIRALDELLI Júnior, Paulo. História da Educação Brasileira. São Paulo: Cortez, 2006.

GOODSON, Ivor F. Currículo: a invenção de uma tradição. In: GOODSON, Ivor F. Currículo: teoria e história. Petrópolis, RJ: Vozes, 2008.

JIMÉNEZ VALLADARES, Juan de Dios; PERALES PALACIOS, Francisco Javier. Aplicación del análisis secuencial al estudio del texto escrito e ilustraciones de los libros de Física y Química de la ESO. Enseñanza de las Ciencias, Barcelona, v. 19, n. 1, p. 3-19, 2001. Disponível em:

https://www.raco.cat/index.php/Ensenanza/article/view/21704. Acesso em: 05 abr. 2020.

KRASILCHIK, Myriam. A evolução no ensino das Ciências no período 1950-1985. In: KRASILCHIK, Myriam. O professor e o currículo de Ciências. São Paulo: EPU; Edusp, 1987.

MACEDO, Elizabeth. A imagem da Ciência: folheando um livro didático. Educação e Sociedade, Campinas, v. 25, n. 86, p. 103-129, 2004. Disponível em: http://www.scielo.br/pdf/es/v25n86/v25n86a07. Acesso em: 4 abr. 2020.

MARCHELLI, Paulo Sergio. Da LDB 4.024/61 ao debate contemporâneo sobre as bases curriculares nacionais. Revista e-Curriculum, São Paulo, v. 12, n. 3, p.14801511, out./dez. 2014. Disponível em:

http://200.144.145.24/curriculum/article/view/21665/15915. Acesso em: 8 abr.2020.

MARTINS, Maria Inês; HOSOUME, Yassuko. Livros didáticos de Física no Brasil: editoras, autores e conteúdos disciplinares: da Reforma Capanema à LDB de 1996. In: SIMPÓSIO INTERNACIONAL LIVRO DIDÁTICO. EDUCAÇÃO E HISTÓRIA, 1., 2007, São Paulo. Anais [...]. São Paulo: Faculdade de Educação da USP, 2007. v. 1. p. 1106-1123

MATHIS, Philip M. Justifying science in an era of vocationalism. Science Education, [s.I.], v. 61, n. 1, p. 99-104, 1977. Disponível em:

https://onlinelibrary.wiley.com/doi/abs/10.1002/sce.3730610111. Acesso em: 02 abr. 2020.

MONTALVÃO, Sérgio. A LDB de 1961: apontamentos para uma história política da 
educação. Mosaico, Rio de Janeiro, v. 2, n. 3, p. 21-39, 2010. Disponível em: http://bibliotecadigital.fgv.br/ojs/index.php/mosaico/article/view/62786/61921. Acesso em: 09 abr. 2020.

MOREIRA, Marco Antonio; AXT, Rolando. O livro didático como veículo de ênfases curriculares no ensino de física. Revista Brasileira de Ensino de Física, São Paulo, v. 8, n. 1, p. 33-48, 1986. Disponível em: http://www.sbfisica.org.br/rbef/pdf/vol08a04.pdf. Acesso em: 01 abr. 2020.

MORTIMER, Eduardo Fleury. A evolução dos livros didáticos de química destinados ao ensino secundário. Em Aberto, Brasília, DF, v. 7, n. 40, p. 25-41, 1988. Disponível em: http://rbep.inep.gov.br/ojs3/index.php/emaberto/article/view/2042. Acesso em: 30 mar. 2020.

SAMPAIO, Glads Maria D’Elia. Obra rara de Física no ensino brasileiro. In: SIMPÓSIO INTERNACIONAL LIVRO DIDÁTICO. EDUCAÇÃO E HISTÓRIA, 1., 2007, São Paulo. Anais [...]. São Paulo: Faculdade de Educação da USP, 2007.

SANTOS, Carlos Alberto dos. A reforma do ensino de Ciências. Ciência Hoje, Rio de Janeiro, 20 jan. 2017. Disponível em: https://cienciahoje.org.br/coluna/a-reforma-doensino-de-ciencias-2. Acesso em: 7 abr. 2020.

SANTOS, Irene da Silva Fonseca dos; PRESTES, Reulcinéia Isabel; DO VALE, Antônio Marques. Brasil, 1930-1961: Escola Nova, LDB e disputa entre escola pública e escola privada. Revista HistedBR Online, Campinas, n. 22, p. 131-149, jun. 2006. Disponível em:

http://www.histedbr.fe.unicamp.br/revista/edicoes/22/art10 22.pdf. Acesso em: 7 abr. 2020.

SAVIANI, Dermeval. História das ideias pedagógicas no Brasil. Campinas: Autores Associados, 2008.

SILVA, Márcio Lima da. A Física no Enem dos anos 2008 e 2009 sob o olhar do movimento: ciência, tecnologia e sociedade. 104 f. Dissertação (Mestrado em Gestão e Práticas Educacionais). Universidade Nove de Julho, São Paulo, 2016. Disponível em: https://bibliotecatede.uninove.br/handle/tede/1354. Acesso em: 01 abr. 2020.

SILVA, Tomaz Tadeu da. Apresentação. In: GOODSON, Ivor F. Currículo: teoria e história. Petrópolis, RJ: Vozes, 2008. p. 7-13.

SUMMERS, Donald B. Are high school chemistry texts up-to-date? Journal of Chemical Education, Washington, DC, v. 37, n. 5, p. 263-264, 1960. Disponível em: https://pubs.acs.org/doi/pdf/10.1021/ed037p263. Acesso em: 1 abr. 2020.

VELHO, Léa. Curso de especialização em jornalismo científico: estudos sociais da ciência e da tecnologia. Campinas: Labjor, 1999.

WUO, Wagner. A Física e os livros: uma análise do saber físico nos livros didáticos adotados para o ensino médio. São Paulo: Educ; Fapesp, 2000. 